\title{
Sensitivity studies with the North Atlantic sigma coordinate Princeton Ocean Model
}

\author{
Tal Ezer *, George L. Mellor \\ Program in Atmospheric and Oceanic Sciences, P.O. Box CN710, Sayre Hall, Princeton University, \\ Princeton, NJ 08544-0710, USA
}

Received 11 September 1998; received in revised form 1 March 1999; accepted 23 May 1999

\begin{abstract}
The sigma coordinate, Princeton Ocean Model (POM) has been configured for the North Atlantic Ocean between $5^{\circ} \mathrm{N}$ and $50^{\circ} \mathrm{N}$ as part of data assimilation, model predictability and intercomparison studies. The model uses a curvilinear orthogonal grid with higher resolution in the western North Atlantic and lower resolution in the eastern North Atlantic. A series of experiments, each one of a 10-year duration, are performed to evaluate the sensitivity of the ocean mean state and variability to model parameters and model configuration; these experiments include open vs. closed boundary conditions, low vs. high resolution grids, and different choices of diffusion and viscosity. The results show that the use of closed boundaries together with near-boundary buffer zones where temperature and salinity are relaxed towards the observed values give less realistic flows, weaker recirculation gyres and less realistic Gulf Stream separation than do open boundary conditions. The experiments show that the sensitivity of the ocean variability in the model to the choice of the Smagorinsky diffusion and viscosity coefficients significantly differs from one region to another and largely depends on other attributes such as the mean position of the Gulf Stream in each simulation. A 50\% change in model resolution in the Gulf Stream region has a larger effect on ocean variability than a change of diffusivity by a factor of 10 . In areas where either the high or the low resolution models have sufficient resolution, as in the Gulf of Mexico, they are able to produce variability comparable to that observed from altimeter data; elsewhere, model variability is underestimated. (C) 2000 Elsevier Science B.V. All rights reserved.
\end{abstract}

Keywords: North Atlantic Ocean; Sigma coordinate; Princeton Ocean Model

\footnotetext{
* Corresponding author.

E-mail address: ezer@splash.princeton.edu (T. Ezer).
} 


\section{Introduction}

High resolution, free surface, sigma coordinate ocean models, based on the Princeton Ocean Model (henceforth POM) numerical code, have been and are being evaluated and compared with other models as part of the development of mesoscale and coastal ocean prediction systems. Two examples are the Data Assimilation and Model Evaluation Experiments (DAMEE, Willems et al., 1994) and the Coastal Ocean Forecast System (COFS, Aikman et al., 1995). In recent years, models such as POM, traditionally used mostly for coastal and regional applications, are being also used for basin scale simulations (e.g., Ezer and Mellor 1994, 1997; Ezer, 1999). Models that use a vertical sigma coordinate grid and a horizontal curvilinear orthogonal grid have characteristics that distinguish them from $z$-level models and thus need special attention in the evaluation of the sensitivity of these models to various parameter and configuration choices. Oey (1996) has shown, for example, using POM, that mesoscale variability in the Gulf of Mexico is quite sensitive to the choice of horizontal diffusion; either too large or too low diffusion results in less realistic variability and frequency of eddy shedding from the loop current. Horizontal diffusion in sigma coordinate ocean models is often formulated along sigma layers (though another approach, not tested here, uses an isopycnally oriented mixing tensor, Barnier et al., 1998); otherwise, transformation to horizontal diffusion results in poor bottom boundary layer representation as detailed by Mellor and Blumberg (1985). This however, entails undesired diapycnal mixing due to the iso-sigma diffusion over steep topographies which is, however, greatly reduced by subtraction of climatological temperature and salinity fields before the diffusion fluxes are calculated. The side effect of this formulation is a weak relaxation tendency towards the prescribed climatology; however, the time-scale associated with this relaxation is relatively long, about 20 years (Ezer and Mellor, 1997), and thus this procedure should not have a significant effect on seasonal and mesoscale variabilities. With high enough resolution, recent experiments with POM have indicated that diffusion and relaxation towards climatology can be nil. It is, in fact, found that coarse resolution sigma coordinate models can tolerate much smaller horizontal viscosity and diffusivities than $z$-level models do (Mellor et al., 2000). Here we test the possibility of zero diffusion, together with a case where climatological fields are not removed from the along-sigma diffusion terms. The study of Mellor et al. (1998), which follows a previous study of pressure gradient errors in sigma coordinate models (Mellor et al., 1994), indicates that reducing diffusion while increasing viscosity may also help in reducing pressure gradient errors. Therefore, we also experiment here with different values for the turbulence Prandtl number, i.e., the mixing coefficient of momentum (viscosity) relative to the mixing coefficient of tracers (diffusion). The main goal of this study is thus to systematically evaluate the sensitivity of the POM to various parameters and resolutions, in a model domain that includes the eddy-rich western boundary current region as well as the open ocean, and uses a curvilinear horizontal grid with irregular grid size.

The paper is organized as follows. First, the model and the experiments are described in Sections 2; then, the effect of lateral boundary conditions and the vorticity balance are discussed in Section 3 and the effects of diffusion and grid size are discussed in Section 4 ; discussion and conclusions are offered in Section 5. 


\section{The model configuration and the experiments design}

The free surface, sigma coordinate POM is described by Blumberg and Mellor (1987). In the experiments described here, 16 vertical sigma layers are used with higher resolution in the upper mixed layer and lower resolution in the deep ocean. (Experiments where bottom boundary layers are also resolved are now being performed.) The horizontal grid employs a curvilinear orthogonal system with a variable resolution covering the domain from $5^{\circ} \mathrm{N}$ to $50^{\circ} \mathrm{N}$ and $0^{\circ} \mathrm{W}$ to $100^{\circ} \mathrm{W}$ (Fig. 1A). Two different grids are used, "low resolution" and "high resolution"; Fig. 1B and C show the average grid size $0.5(\Delta x+\Delta y)$ in the two grids. In the high resolution model, $\Delta y$ is as small as about $8 \mathrm{~km}$ in the Gulf of Mexico; in most of the domain $\Delta x>\Delta y$. The use of a curvilinear grid allows us to better resolve the US coastal regions and the regions of intense meso-scale variabilities such as the Gulf Stream, the Gulf of Mexico and the Caribbean Sea; however, in most of the domain even the high resolution grid is only marginally eddy resolving. To minimize pressure gradient errors, the bottom topography in the model (not shown) has been smoothed such that the difference of the depths of adjacent grid points divided by their mean is less than 0.4 (Mellor et al., 1994). The use of higher resolution in the Western North Atlantic reduces smoothing on the continental shelf break and slope. The maximum ocean depth in the model is $5500 \mathrm{~m}$ and the minimum depth is $10 \mathrm{~m}$.

The vertical mixing coefficients are provided by the Mellor and Yamada (1982) turbulence scheme (the so-called level 2.5 version). The horizontal mixing coefficients for momentum (viscosity) and tracers (diffusivity) are calculated by a Smagorinsky-type formulation (Smagorinsky et al., 1965) such that:

$$
\left(A_{\mathrm{M}}, A_{\mathrm{H}}\right)=\left(C_{\mathrm{vis}}, C_{\mathrm{dif}}\right) \Delta x \Delta y\left[\left(\frac{\partial u}{\partial x}\right)^{2}+\frac{1}{2}\left(\frac{\partial v}{\partial x}+\frac{\partial u}{\partial y}\right)^{2}+\left(\frac{\partial v}{\partial y}\right)^{2}\right]^{1 / 2}
$$

where $u$ and $v$ are the horizontal velocity components in the $x$ and $y$ direction, respectively ( $x$ and $y$ are along the curvilinear model grid lines). Therefore, horizontal viscosity and diffusion are reduced with decreasing grid size and velocity gradients. Sensitivity experiments will use different values of the coefficients $C_{\text {vis }}$ and $C_{\text {dif }}$, and will thus represent different values of the turbulent Prandtl number, $\operatorname{Pr}=C_{\mathrm{vis}} / C_{\mathrm{dif}}$. The change of temperature due to the iso-sigma horizontal diffusion, as discussed before and detailed in Mellor and Blumberg (1985), can be written as:

$$
\frac{\partial T}{\partial t}=\frac{\partial}{\partial x}\left(A_{\mathrm{H}} \frac{\partial\left(T-T_{\text {clim }}\right)}{\partial x}\right)+\frac{\partial}{\partial y}\left(A_{\mathrm{H}} \frac{\partial\left(T-T_{\text {clim }}\right)}{\partial y}\right)
$$

where $T_{\text {clim }}(x, y, z)$ represents climatological data. A similar formulation applies also to salinity. In one experiment, $T_{\text {clim }}$ will be set to zero.

All the experiments start with the same initial condition, the January climatological temperature and salinity data of the Generalized Digital Environmental Model (GDEM) (Teague et al., 1990), and forced by the same surface wind stress, the monthly 
(A) MODEL GRID (LOW RES.)

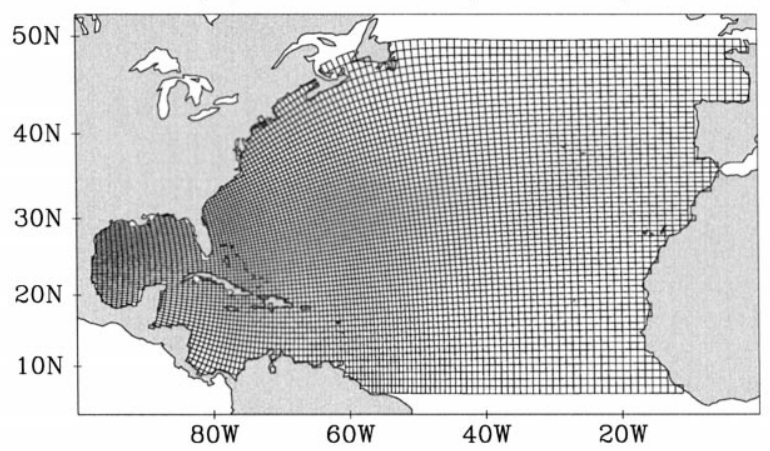

(B) AVR. GRID SIZE (LOW RES.)

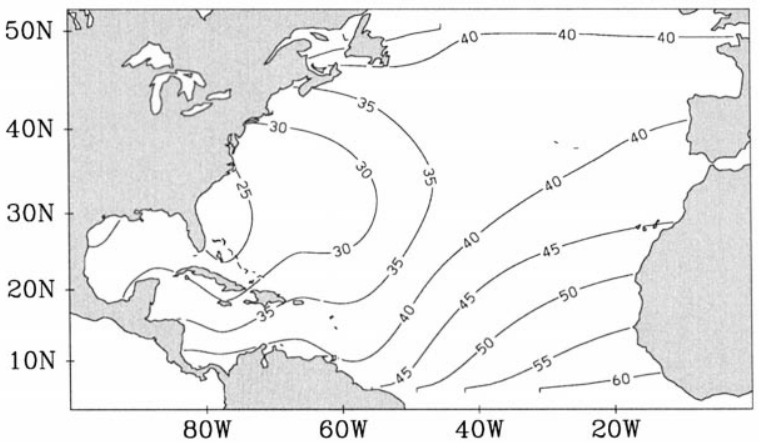

(C) AVR. GRID SIZE (HIGH RES.)

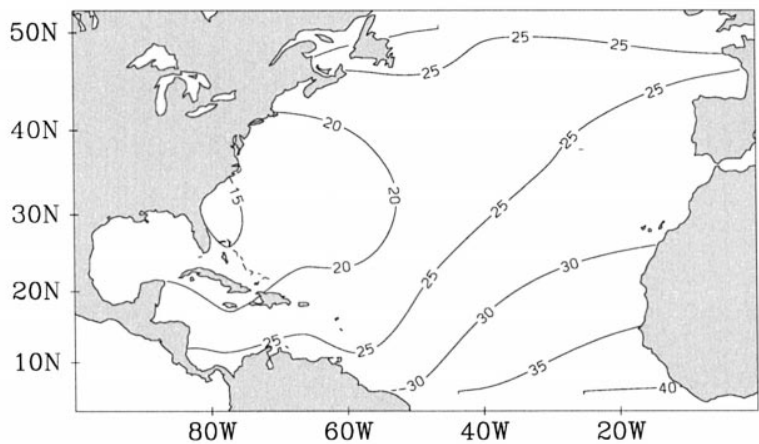

Fig. 1. (A) The curvilinear model grid of the low resolution version of the model, the average grid size (in kilometers) of the low resolution (B) and the high resolution $(\mathrm{C})$ domains.

climatological wind stress of the Comprehensive Ocean-Atmosphere Data Set (COADS) as analyzed by da Silva et al. (1994). Surface heat flux $(Q)$ is calculated according to:

$$
Q=Q_{\mathrm{c}}+\left(\frac{\partial Q}{\partial T}\right)_{\mathrm{c}}\left(T_{\mathrm{c}}^{0}-T^{0}\right)
$$


where subscript "c" represents SST fields derived from the COADS monthly climatology, and $T^{0}$ is the model surface temperature. This Haney-type formulation (Haney, 1971), which adds a simplified atmospheric feedback term to the observed fluxes, has been used in several previous studies using POM (Ezer and Mellor, 1992, 1994). Evaporation and precipitation data from COADS are used for surface salinity flux conditions. However, in order to reduce unrealistic salinity changes in the mixed layer, we found it necessary to add a weak relaxation of salinity to the monthly climatology in the upper five layers of the model; with relaxation time-scale ranging from 30 days at the surface to 360 days at level 5 (the depth of level 5 corresponds to $0.1 \mathrm{~m}$ in the shallowest regions and about $70 \mathrm{~m}$ in the deepest points).

Lateral boundary conditions for temperature and salinity are provided by three $3^{\circ}$ wide buffer zones, in the north, south and in the eastern portion bordering the Gibraltar Straits where model fields are relaxed towards the GDEM monthly climatology with relaxation time scale ranging from 5 days near the boundary to 60 days at the outer edge of the buffer zone. The experiment with closed boundaries has zero velocities perpendicular to the boundaries; a strategy quite common in basin scale models. The hope is that velocities will geostrophically adjust to the density field within the buffer zone.

In the experiments with open boundary conditions, inflow/outflows on the northern and southern open boundaries are taken from the annual mean velocities derived from the whole Atlantic model of Ezer and Mellor (1997); their vertically integrated values are shown in Fig. 2. The imposed transports in the northern boundary includes about 25 $\mathrm{Sv}$ of slope water inflow at the north western corner of the domain, and a similar amount of outflow transport representing the North Atlantic Current. The imposed transports in

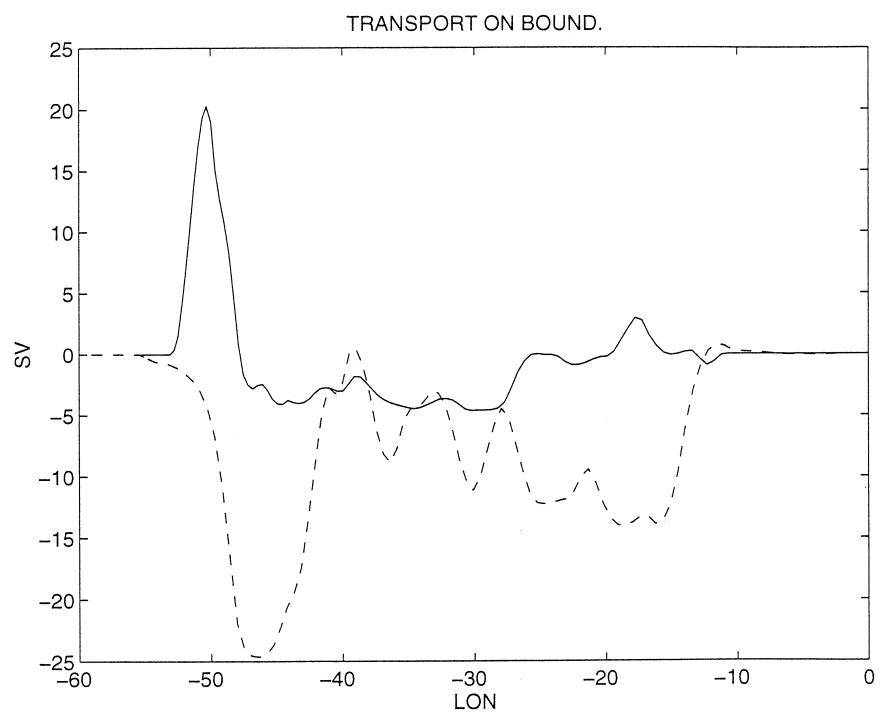

Fig. 2. The imposed total stream function (in Sverdrups) along the southern boundary (solid line) and along the northern boundary (dashed line), derived from the vertically and annually averaged flow in the whole Atlantic model of Ezer and Mellor (1997). 
Table 1

The model configuration and parameters used in the experiments. $C_{\mathrm{vis}}$ and $C_{\mathrm{dif}}$ are the coefficients of the Smagorinsky formulation for viscosity and diffusivity in Eq. (1), respectively; $\operatorname{Pr}=C_{\mathrm{vis}} / C_{\mathrm{dif}}$ is the turbulent Prandtl number; $T_{\text {clim }}$ and $S_{\text {clim }}$ are the climatological fields used in Eq. (2)

\begin{tabular}{lllllll}
\hline Experiment & Resolution & Boundary conditions & $C_{\text {vis }}$ & $C_{\text {dif }}$ & $P r$ & $T_{\text {clim }}, S_{\text {clim }}$ \\
\hline L1 & Low & Closed & 0.1 & 0.1 & 1 & GDEM \\
L2 & Low & Open & 0.1 & 0.1 & 1 & GDEM \\
L3 & Low & Open & 0.1 & 0 & $\infty$ & N/A \\
L4 & Low & Open & 0.01 & 0.01 & 1 & GDEM \\
L5 & Low & Open & 0.1 & 0.1 & 1 & 0 \\
H1 & High & Open & 0.01 & 0.01 & 1 & GDEM \\
H2 & High & Open & 0.1 & 0.01 & 10 & GDEM \\
H3 & High & Open & 0.1 & 0.1 & 1 & GDEM \\
\hline
\end{tabular}

the southern boundary includes about $20 \mathrm{~Sv}$ inflow along the South American coast and a similar amount of outflow along the rest of the boundary.

The experiments are summarized in Table 1. A comparison between experiments L1 and L2 will indicate the effect of the lateral boundary condition, while comparisons between L2, L3, L4 and L5 will indicate the effect of diffusion and viscosity in the low resolution experiments. In experiment L3 horizontal diffusion is nil (thus $T_{\text {clim }}$ and $S_{\text {clim }}$ in Eq. (2) are irrelevant) and, thus, is unique in ocean modeling. In L5, $T_{\text {clim }}$ and $S_{\text {clim }}$ are set to zero in Eq. (2). A comparison of L2 vs. H3 and L4 vs. H1 will indicate the effect of model resolution under similar parameterization; however one should keep in mind that, for the same diffusion coefficient the actual diffusivity in Eq. (1) is not the same since it depends on grid size and velocity gradients which differ from case to case. The diffusivity calculated from Eq. (1) varies spatially, temporally and from case to case. For example, at 50-m depth, $A_{\mathrm{H}}$ in the low resolution experiments with $C_{\mathrm{dif}}=0.1$ varies between $\sim 100 \mathrm{~m}^{2} \mathrm{~s}^{-1}$ in the open ocean and a maximum of $\sim 2000 \mathrm{~m}^{2} \mathrm{~s}^{-1}$ in the Gulf Stream region, while at 4000-m depth, values range from $\sim 20$ to $\sim 500 \mathrm{~m}^{2}$ $\mathrm{s}^{-1}$. Values of $A_{\mathrm{H}}$ in the high resolution experiments with the same value of $C_{\text {dif }}$ are about $40 \%$ lower than those in the low resolution calculations.

\section{Open vs. closed boundary conditions}

In this section, experiments L1 and L2 are compared. Initially, during the first year or so, the two experiments produce quite similar flow fields, as they represent calculations that are quite similar to diagnostic calculations (Ezer and Mellor, 1994), i.e., the flow field is adjusted to the observed density field which has not departed significantly from the climatology used as initial conditions. The average vertically integrated stream functions of year 2 in the two experiments are shown in Fig. 3. The structure of the two simulations is very similar in most of the domain, except in the Gulf Stream region. With closed boundaries (Fig. 3A) the southward western boundary inflow from the 
(A) STREAM FUNC. YEAR 2 (CLOSED BC)

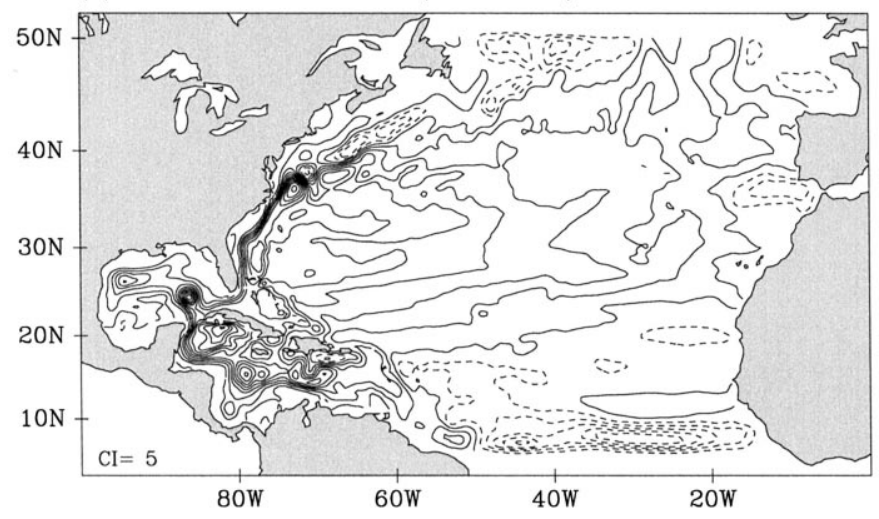

(B) STREAM FUNC. YEAR 2 (OPEN BC)

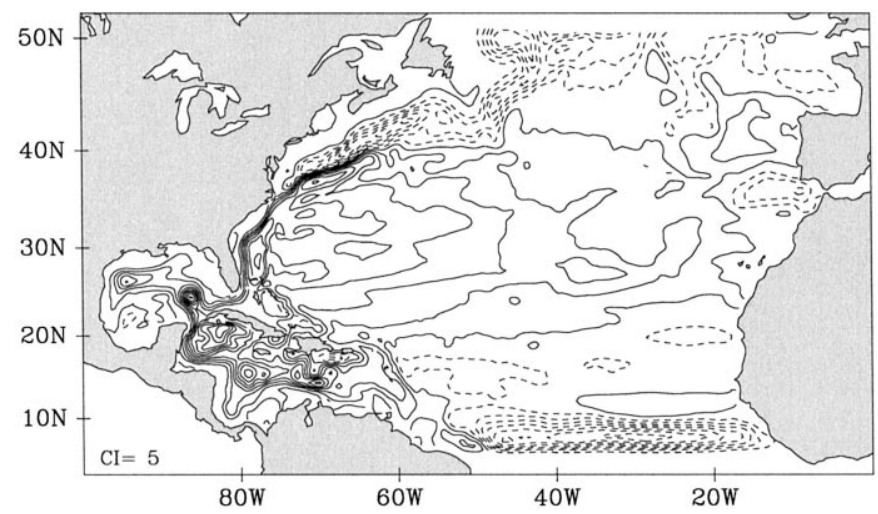

Fig. 3. Averaged stream function of year 2 of the integration. (A) Experiment L1 with closed boundary conditions, and (B) experiment L2 with open boundary conditions. Contour interval is $5 \mathrm{~Sv}$; dashed lines represent negative values.

northern boundary is relatively weak and so is the recirculation gyre north of the Gulf Stream which is detached from the inflow boundary current. The result is an unrealistic Gulf Stream separation downstream of Cape Hatteras. The separation problem is typical for many basin scale models such as the Community Modeling Effort (CME) model (Beckmann et al., 1994). The circulation and the Gulf Stream separation is more realistic in the case with open boundaries (Fig. 3B); in particular, note the unrealistic anticyclonic gyre just off Cape Hatteras that is seen in Fig. 3A, but not in Fig. 3B.

After 10 years, both models show less realistic Gulf Stream separation than in year 2; however, there are clear differences between the two simulations. First, just off Cape Hatteras an unrealistic anticyclonic gyre with as much as $40 \mathrm{~Sv}$ is evident in L1; this gyre is much weaker in L2. Second, downstream of Cape Hatteras, around $55^{\circ} \mathrm{W}$, both simulations show some evidence of the cyclonic northern recirculation gyre (i.e., a local 
minimum in the stream function), an observed feature (Hogg et al., 1986), but the intensity of this gyre is much smaller in L1 (Fig. 4A) than in L2 (Fig. 4B). The maximum total southwestward transport between the coast and the center of this gyre is about $25 \mathrm{~Sv}$ in L2, but less then $5 \mathrm{~Sv}$ in L1. The open boundary condition, allows larger inflow transport, compared to the closed boundary conditions; this inflow of cold slope water is needed to support the circulation in the northern recirculation gyre, as previously shown in the Gulf Stream separation study of Ezer and Mellor (1992). The separation of the Gulf Stream, though improved with the open boundary conditions, is still not satisfactory (this is also evident in the surface elevation fields, shown later), and even the higher resolution grid in experiments $\mathrm{H} 1-\mathrm{H} 3$ is not sufficiently fine to solve the problem. It is quite possible that prescribing more realistic, high resolution temperature and velocity fields on the northern boundary (from models or data) will improve the simulations in this domain. Although the separation of the Gulf Stream in ocean models

(A) STREAM FUNC. YEAR 10 (CLOSED BC)

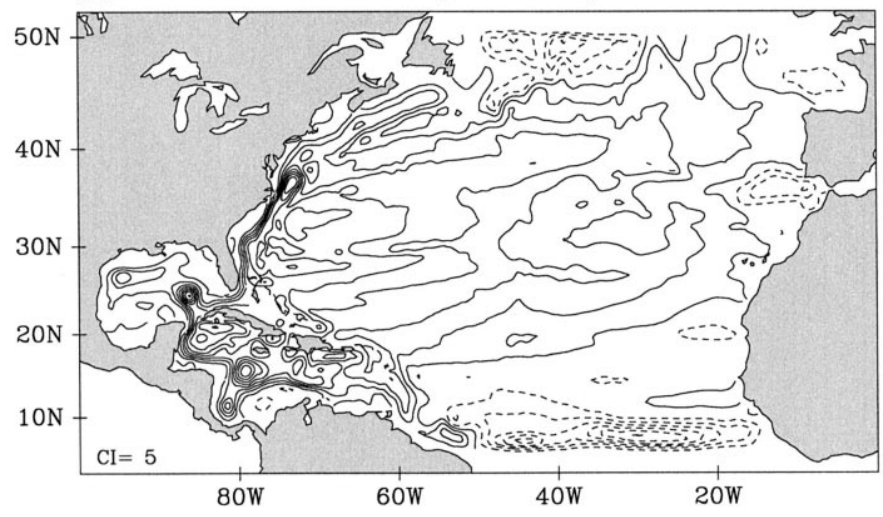

(B) STREAM FUNC. YEAR 10 (OPEN BC)

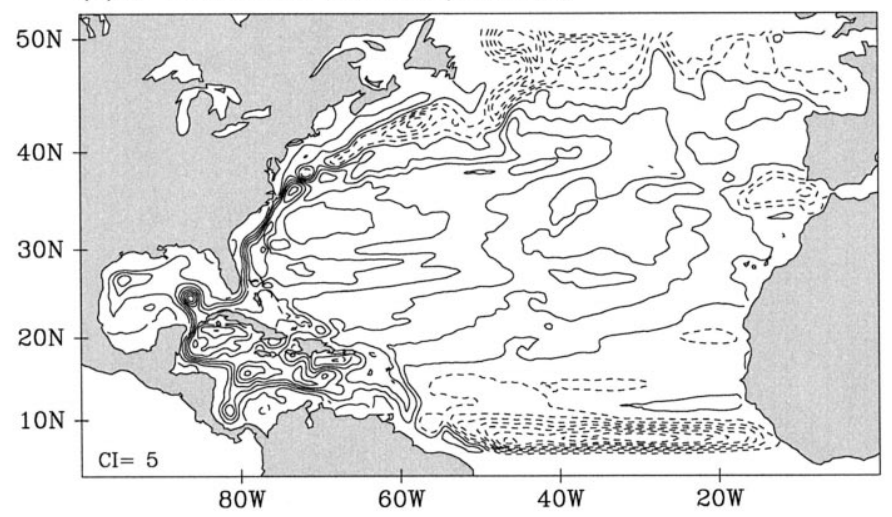

Fig. 4. Same as Fig. 3, but for year 10. 
is still not completely understood, recent studies indicate the important role played by the Joint Effect of Baroclinicity and Bottom Relief (the JEBAR effect) (Myers et al. 1996; Dengg et al., 1996). Therefore, models need to maintain the baroclinic structure north of the Gulf Stream (i.e., by the southward flowing cold water inflow) in order to achieve realistic separation. For the domain and the model used here, it seems clear (Fig. 4) that the northern buffer zone by itself cannot produce the appropriate barotropic flow needed to maintain the northern recirculation gyre.

(A) CORIOLIS TERM

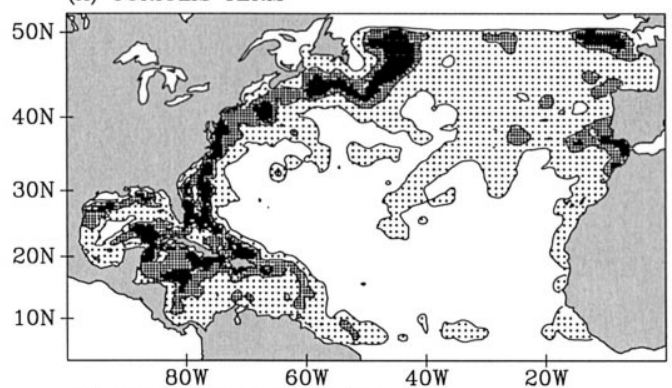

(B) BOTTOM PRESSURE TERM

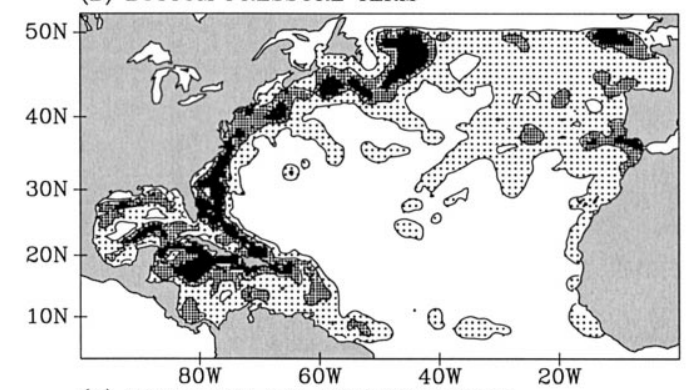

(C) ADVECTION AND DIFFUSION TERM

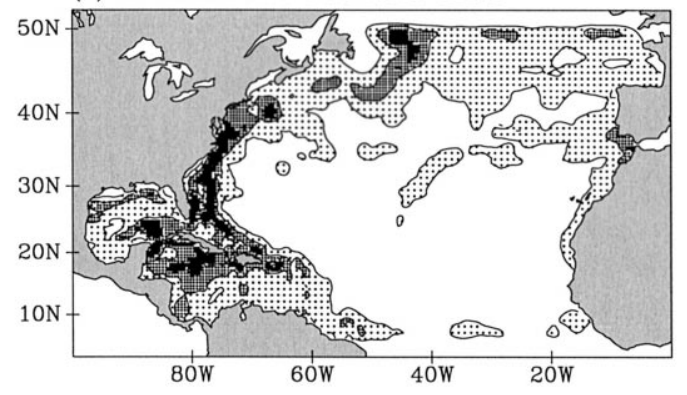

Fig. 5. The absolute value of the leading terms in the vertically integrated vorticity balanced equation averaged over year 11 of experiment L2: (A) The Coriolis term, (B) the bottom pressure torque term and (C) the advection and diffusion terms. Dotted areas represent values between $1-5 \times 10^{-9} \mathrm{~m} \mathrm{~s}^{-2}$, light shaded areas represent values between $5-10 \times 10^{-9} \mathrm{~m} \mathrm{~s}^{-2}$ and dark shaded areas represent values greater than $10 \times 10^{-9}$ $\mathrm{m} \mathrm{s}^{-2}$. 
To further investigate the dynamical balance in the model, we now diagnose the terms in the vertically integrated vorticity balance equation:

$$
\begin{gathered}
\frac{\partial}{\partial t}\left(\frac{\partial \bar{v} D}{\partial x}-\frac{\partial \bar{u} D}{\partial y}\right)+\frac{\partial A_{y}}{\partial x}-\frac{\partial A_{x}}{\partial y}+\frac{\partial(f \bar{u} D)}{\partial x}+\frac{\partial(f \bar{v} D)}{\partial y} \\
=\frac{\partial P_{\mathrm{b}}}{\partial x} \frac{\partial D}{\partial y}-\frac{\partial P_{\mathrm{b}}}{\partial y} \frac{\partial D}{\partial x}+\frac{\partial\left(\tau_{y \mathrm{o}}-\tau_{y \mathrm{~b}}\right)}{\partial x}-\frac{\partial\left(\tau_{x \mathrm{o}}-\tau_{x \mathrm{~b}}\right)}{\partial y},
\end{gathered}
$$

where overbars indicate vertical averages. See Ezer and Mellor (1994) for more details on the derivation of Eq. (4) and how these terms are calculated in POM. $P_{\mathrm{b}}$ is the bottom pressure:

$$
P_{\mathrm{b}}=g \eta+\int_{-H}^{\eta} \rho g \mathrm{~d} z
$$

$\rho$ is the density, $f$ is the Coriolis parameter, $\eta$ is the surface elevation, $D=H+\eta$, $\left(A_{x}, A_{y}\right)$ represents the advection and diffusion terms (typically, advection is an order of magnitude larger than diffusion of momentum), $\left(\tau_{x}, \tau_{y}\right)_{\mathrm{o}}$ and $\left(\tau_{x}, \tau_{y}\right)_{\mathrm{b}}$ are the surface

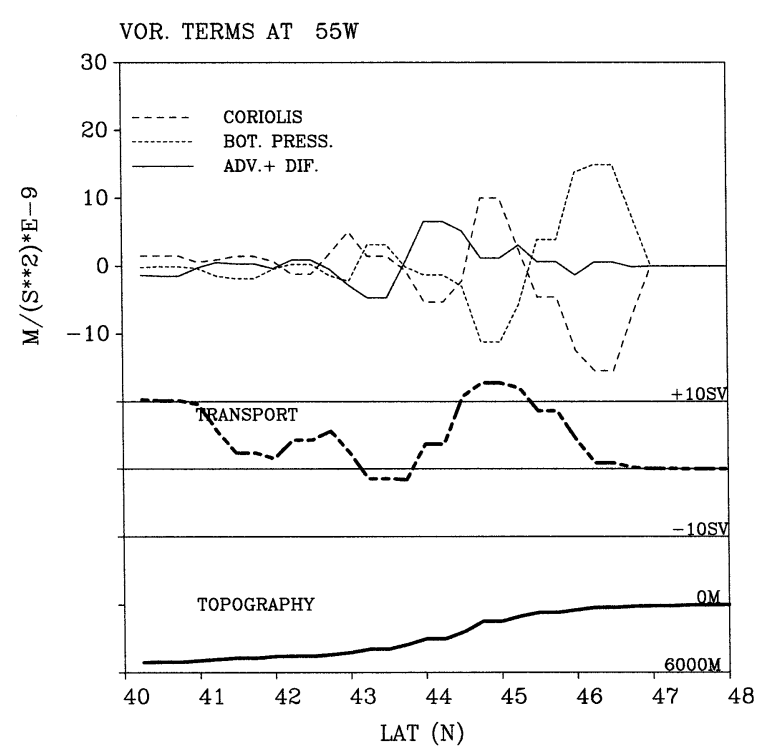

Fig. 6. The balance of the leading terms in the vertically integrated vorticity balanced equation averaged over year 11 of experiment L1 with closed boundary conditions. The cross-section is at $55^{\circ} \mathrm{W}$. The Coriolis term, the bottom pressure torque term and the advection and diffusion terms are indicated by the dashed, dotted and solid lines, respectively, at the top of the figure (units on the left are in $10^{-9} \mathrm{~m} \mathrm{~s}^{-2}$ ). Also shown are the vertically averaged transport (a heavy long and short dash line) and the bottom topography (heavy solid line at the bottom of the figure). 
and bottom stress, respectively. The terms on the left side of Eq. (4) are the tendency term, advection and diffusion terms, and Coriolis term. The terms on the right side are the bottom pressure torque term, and the surface and bottom stress curl terms. For steady flows, $\partial(\bar{u} D) \partial x+\partial(\bar{v} D) / \partial y=0$, and the Coriolis dominated term becomes the beta term, $\beta \bar{v} D$ where $\beta \equiv \partial f / \partial y$.

Fig. 5 shows the absolute value of the leading terms in Eq. (4) obtained from a 1-year average following the 10- year calculations of experiment L2. Near topographical features such as the Mid-Atlantic Ridge and the New England Seamount Chain, the Coriolis term and the bottom pressure torque term have similar spatial distribution and, in fact, balance each other (not shown); the advection and diffusion term is the third leading term in magnitude. The largest amplitudes are found near the western boundary and the Caribbean Sea where strong flows interact with bottom topography.

We now examine the differences between the open and the closed boundary simulations in a section at $55^{\circ} \mathrm{W}$ which cuts across the northern recirculation gyre and the Gulf Stream. Figs. 6 and 7 show the balance of the leading terms of Eq. (4) in L1 and in L2; also shown are the vertically averaged transports and the bottom topography along this section. With closed boundaries (L1), an eastward (positive) transport of about $13 \mathrm{~Sv}$, associated with an unrealistic branch of the Gulf Stream flowing along the continental slope is evident between $45^{\circ} \mathrm{N}$ and $46^{\circ} \mathrm{N}$ (Fig. 6), while with open boundaries (L2) this flow is much weaker, about $4 \mathrm{~Sv}$ (Fig. 7). Compared to the above eastward transport, the return westward transport south of the eastward flow and north of the Gulf Stream, between $44^{\circ} \mathrm{N}$ and $45^{\circ} \mathrm{N}$, is stronger in $\mathrm{L} 2$ than in $\mathrm{L} 1$, so that the total westward transport at this section is about $-13 \mathrm{~Sv}$ in L2 and only $-2 \mathrm{~Sv}$ in L1. Concomitantly, the bottom pressure torque is larger by a factor of 2 in L2 (Fig. 7)

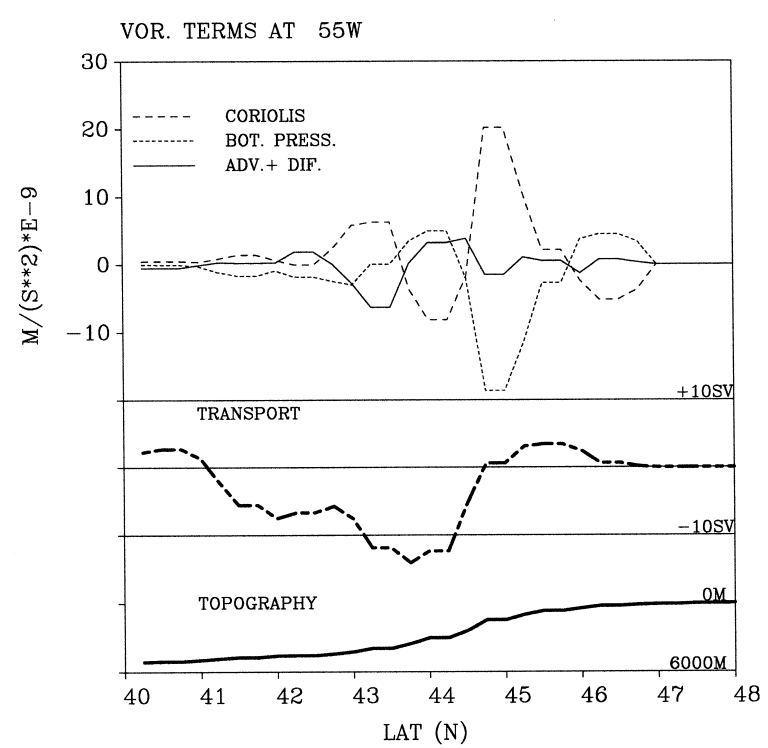

Fig. 7. Same as Fig. 6, but for experiment L2 with open boundary conditions. 
compared to L1 (Fig. 6), indicating the influence that the prescribed slope water inflow transports in L2 has on the northern recirculation gyre, as discussed before. The balance of terms in the vorticity equation indicate that near the Gulf Stream, around $43.5^{\circ} \mathrm{N}$, the Coriolis term is balanced by the advection and diffusion terms and by the bottom pressure term. On the continental slope, and in particular at the edge of the return westward flow, around $45^{\circ} \mathrm{N}$, the main balance is between the Coriolis and the bottom pressure torque terms. While these calculations and analysis demonstrate qualitatively the non-negligible effect of the choice of boundary conditions on the Gulf Stream separation, transport and dynamic balance in a coarse resolution model, further improvement in the boundary conditions and in particular in resolution are clearly needed in order to achieve a more realistic simulations of the Gulf Stream.

\section{Effect of diffusion, viscosity and model resolution}

To test the vertical mixing component associated with the iso-sigma diffusion as formulated in Eq. (2), the area averaged vertical profiles of temperature and salinity after 10 years of model integration are shown in Fig. 8; experiments L2 (with large diffusion), L3 (with zero diffusion) and L5 (with $T_{\text {clim }}$ and $S_{\text {clim }}$ set to zero) are compared with the initial condition. The model climate drift at the surface is larger in the temperature field than in the salinity field, due to the different surface boundary conditions used for temperature and salinity. The climate drift is manifest in a reduction of gradients across the main halocline and thermocline. Experiment L5, where climatological data were not subtracted in Eq. (2), has undesired diapycnal mixing and thus has the maximum drift, while experiments L2, L3 (and L4, not shown) have smaller climate drift. The fact that the case with no diffusion (L3) has climate drift similar to the one with high diffusion but with the subtraction of climatology (L2) indicates that the change in the vertical structure in L2 and L3 is most likely the result of vertical mixing and lateral advection from the boundaries and not the side effect of the iso-sigma horizontal diffusion. The weak relaxation to climatology associated with the formulation of diffusion in the model (i.e., the diffusion of anomalies relative to climatology) seems to have only a very small, but positive, effect by slightly reducing the model climate drift (as in L2) compared with the case with no diffusion (L3). The procedure invoked in Eq. (2) has been used in numerous studies that show little negative effect on model properties, other than the removal of the unrealistic diapycnal mixing seen in L5. We note that experiment L3 produces somewhat noisier temperature fields indicating that a choice of parameters similar to L2 is preferred in most low resolution applications when iso-sigma diffusion is used.

The area averaged mean kinetic energy (MKE) and eddy kinetic energy (EKE) are shown in Fig. 9. Experiments L1, L2 and L3 show very similar EKE and MKE (Fig. 9a-c), with only slightly larger EKE in the case with zero diffusion (L3, Fig. 9c); experiment L4, with reduced viscosity, shows significantly larger EKE (Fig. 9d), due to larger variability in the velocity fields in the Gulf of Mexico and in the Gulf Stream regions. 
(A) AREA AVR. TEMPERATURE (JAN)

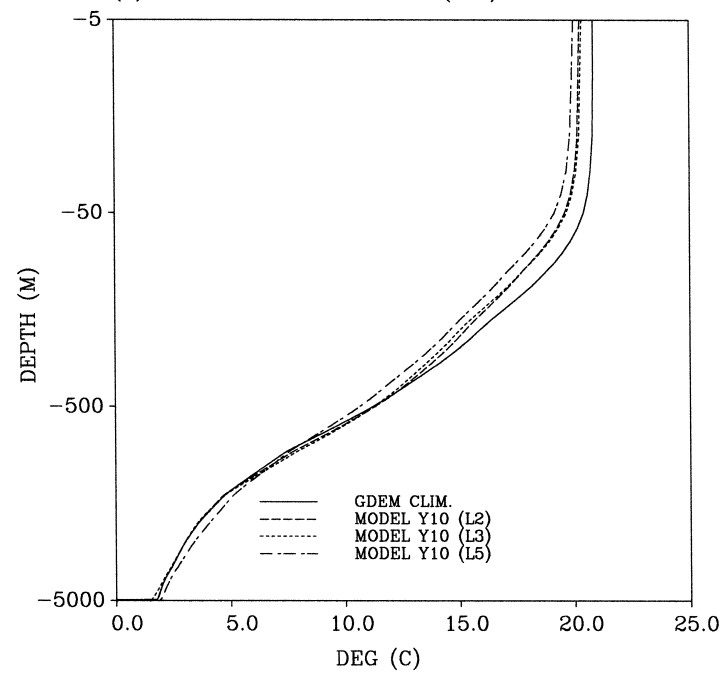

(B) AREA AVR. SALINITY (JAN)

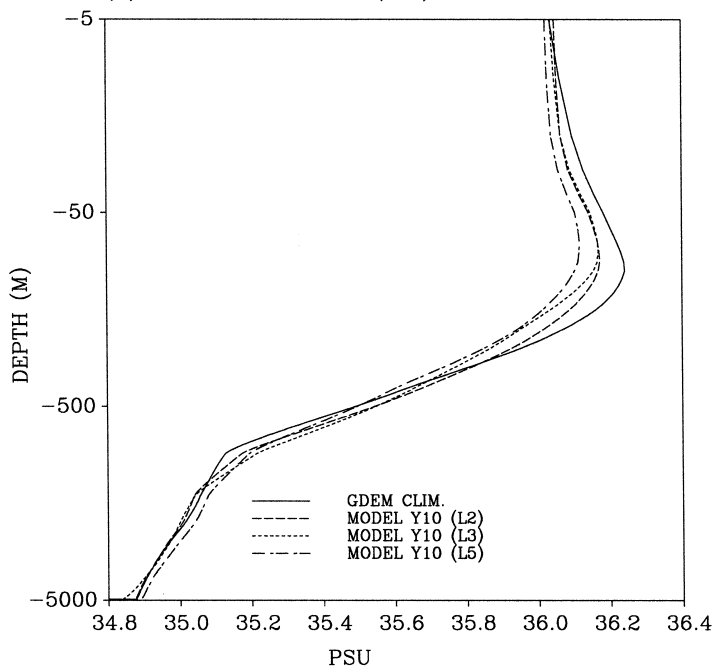

Fig. 8. Vertical profiles of area averaged and monthly averaged (January) temperature (A) and salinity (B) of the initial condition (the GDEM climatology, solid lines) and the model runs after 10 years. Note that the vertical coordinate is logarithmic.

Fig. 10 shows the area averaged rms elevation anomaly during the 10 -year simulations, for experiments L2 and H3 (with high diffusivity, upper panels) and experiments L4 and H1 (with low diffusivity, lower panels). The analysis is done separately for the western North Atlantic region which includes the Gulf Stream, the Caribbean Sea and the Gulf of Mexico, and for the eastern North Atlantic which includes the rest of the model domain. The spinup of surface variability in both grids takes about 3 years, after 

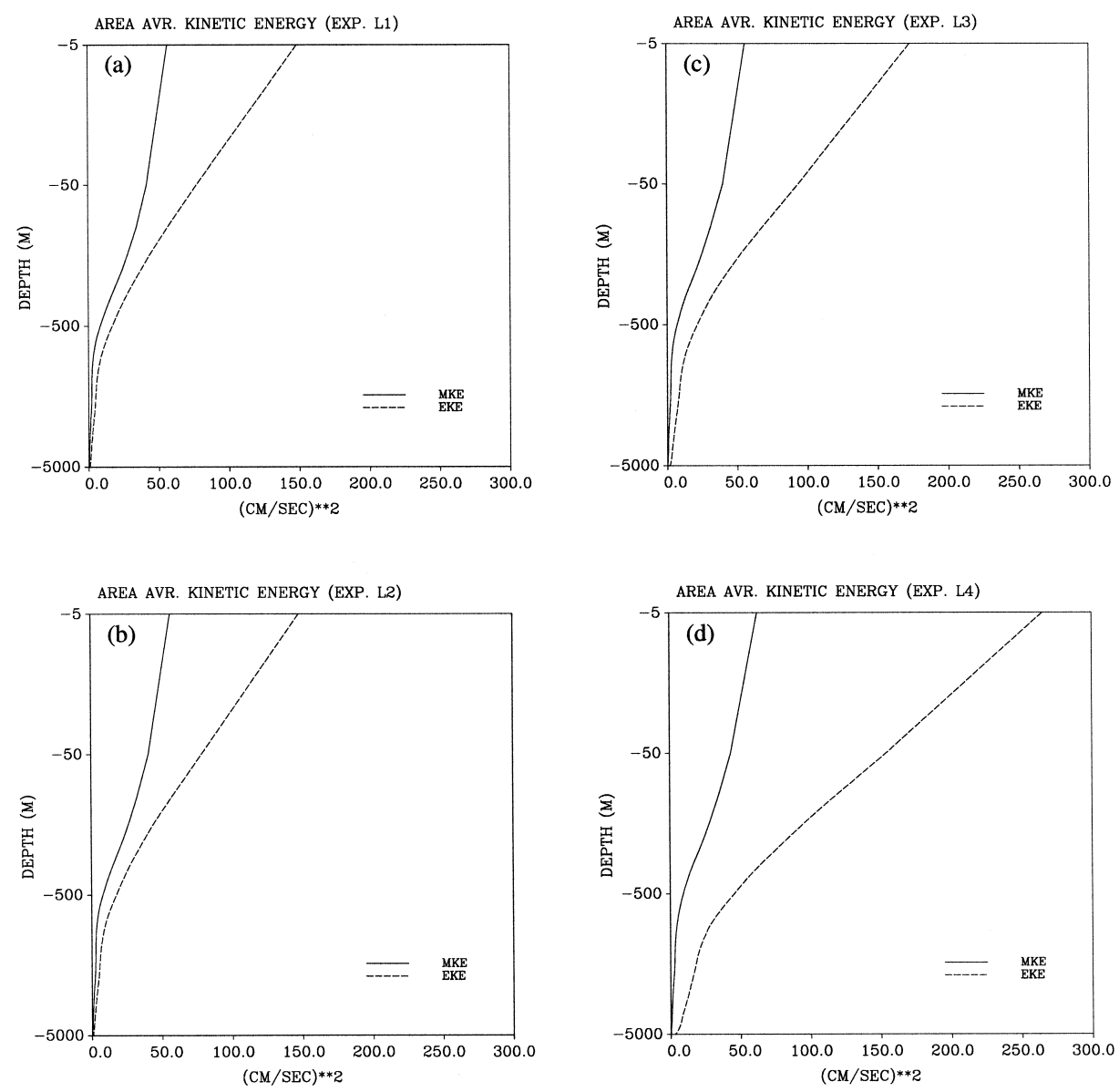

Fig. 9. Vertical profiles of area averaged MKE (solid lines) and EKE (dashed lines), for experiments (a) L1, (b) L2, (c) L3 and (d) L4. Values are energy per unit mass (in $\mathrm{cm}^{2} \mathrm{~s}^{-2}$ ). Note that the vertical coordinate is logarithmic.

which variability does not change much, except for seasonal variations. Over the western North Atlantic (Fig. 10a and b), the high resolution grid provides higher levels of variability due to the better resolution of the western boundary currents. However, there is no significant differences between the two grids in the variability over the eastern portion of the domain (Fig. 10c and d), where both model grids are non-eddy resolving. Note also that the seasonal and interannual variations in the western portion of the domain are much larger in the western portion of the domain than they are in the eastern portion. The reduction of the horizontal diffusion by a factor of 10 has only small effect on the mean level of variability (i.e., comparing the upper and lower panels of Fig. 10), though in the western sub-region, interannual variations are affected by the diffusion causing a less regular annual cycle in the case with reduced diffusion. 

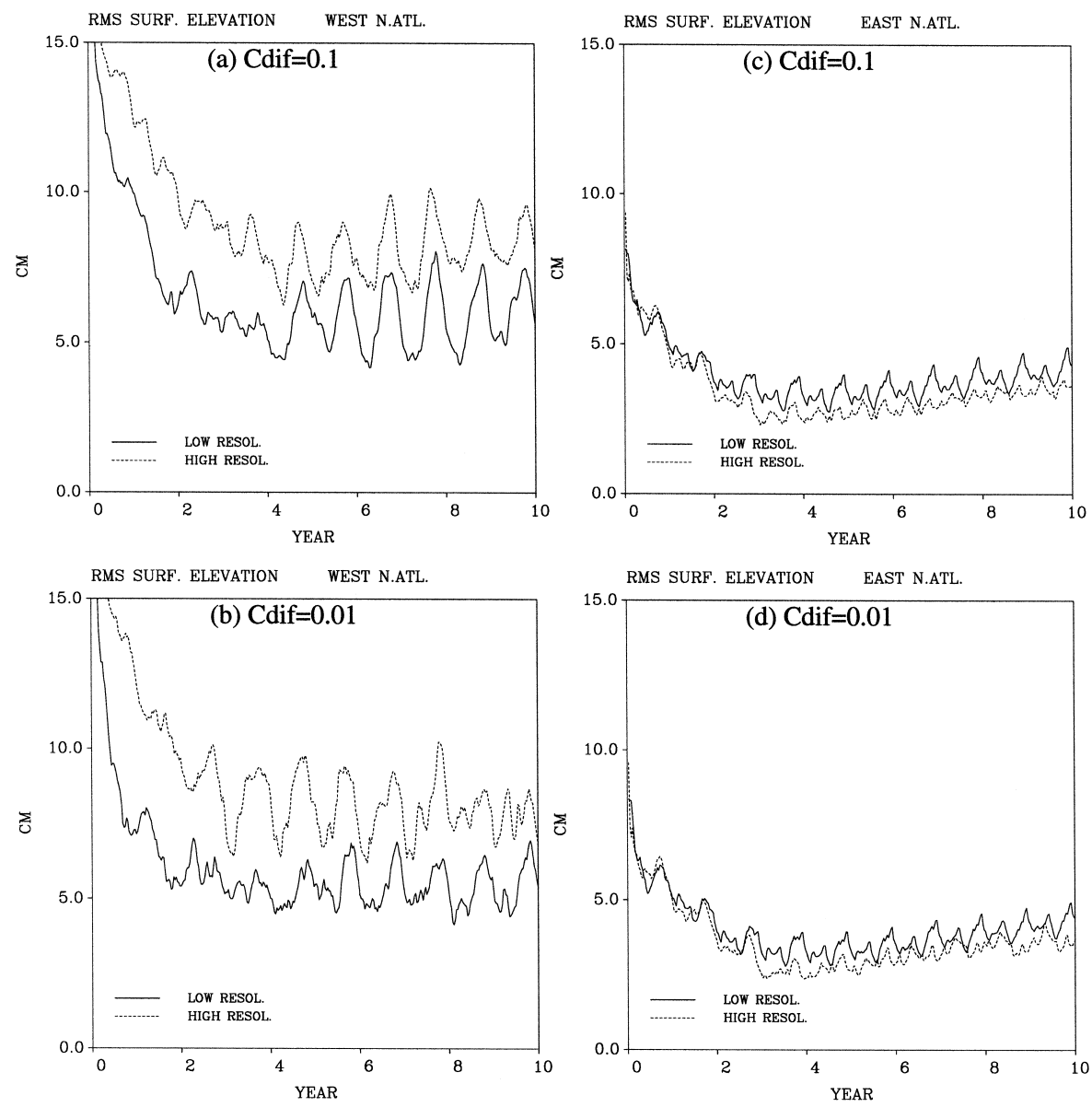

Fig. 10. Rms surface elevation anomaly vs. time of integration calculated over the western North Atlantic (left panels) and over the eastern North Atlantic (right panels); solid lines are for low resolution calculations and dashed lines are for high resolution calculations. (a) Experiments L2 and H3, (b) L4 and H1, (c) L2 and H3 and (d) L4 and H1. The value of the diffusion coefficient is indicated in each figure.

We now look at the spatial distribution of the mean and variability of surface elevation, first in the low resolution calculations in Figs. 11 and 12 and then in the high resolution calculations in Figs. 13 and 14. The 3-year mean (years 4-6, after the spinup is completed; see Fig. 10) of surface elevation in the low resolution calculations exhibits the Gulf Stream separation problem discussed before and in previous studies (Ezer and Mellor, 1992; Beckmann et al., 1994; Dengg et al., 1996; Myers et al., 1996). The surface current in the model has two branches, one is separated from the coast and represents the observed Gulf Stream, and another one continues to flow along the coast and in some cases separates from the coast farther downstream. The latter unrealistic current is a typical feature of many models with insufficient resolution. The differences 
(A) MEAN SURF. ELEV. (EXP. L2)

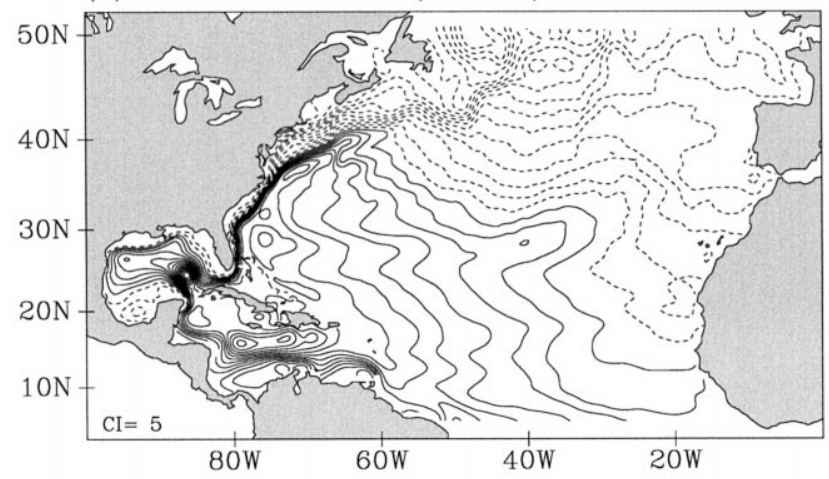

(B) MEAN SURF. ELEV. (EXP. L3)

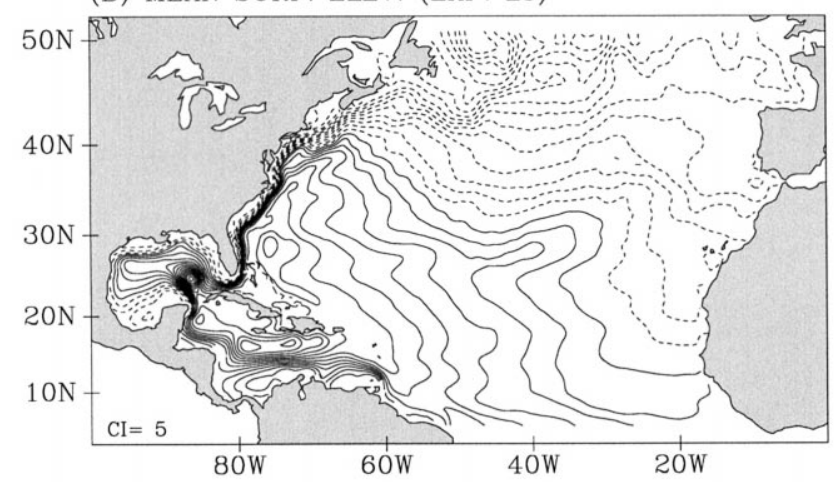

(C) MEAN SURF. ELEV. (EXP. L4)

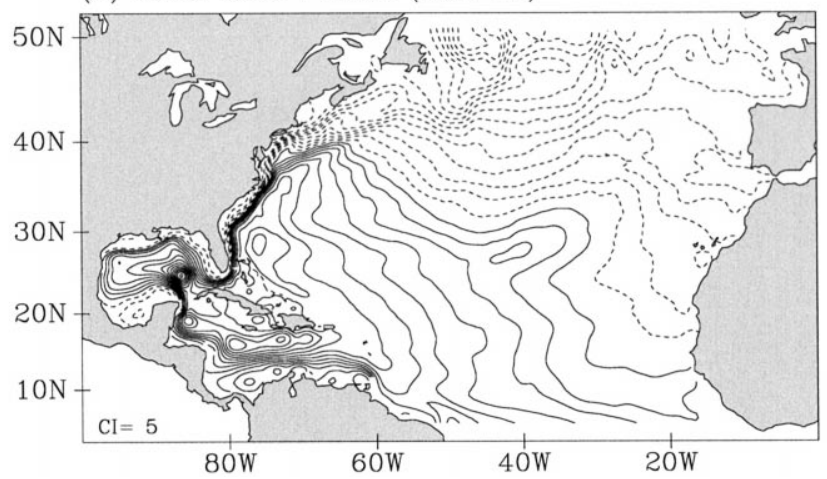

Fig. 11. Mean surface elevation calculated from 3 years (years 4-6) of integration with the low resolution grids of experiments (A) L2, (B) L3 and (C) L4. Contour interval is $5 \mathrm{~cm}$ and dashed lines represent negative contours.

in the mean Gulf Stream between the different low resolution calculations are quite small, though in experiment L2 with higher diffusivity (Fig. 11A) the Gulf Stream 
(A) RMS SURF. ELEV. (EXP. L2)

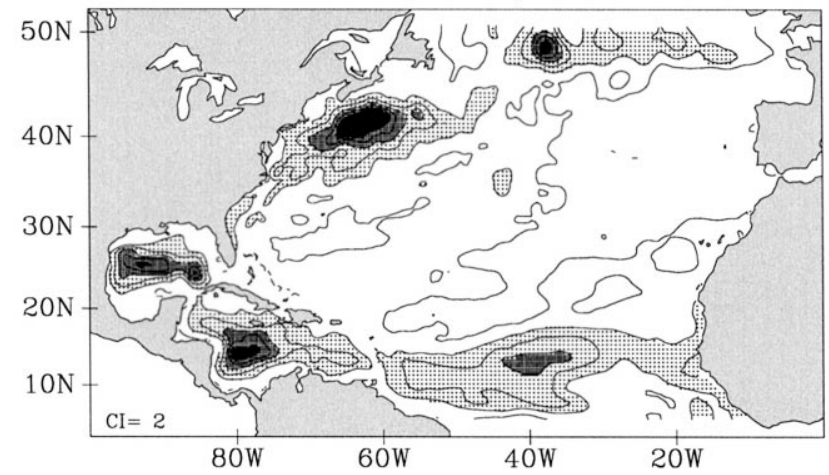

(B) RMS SURF. ELEV. (EXP. L3)

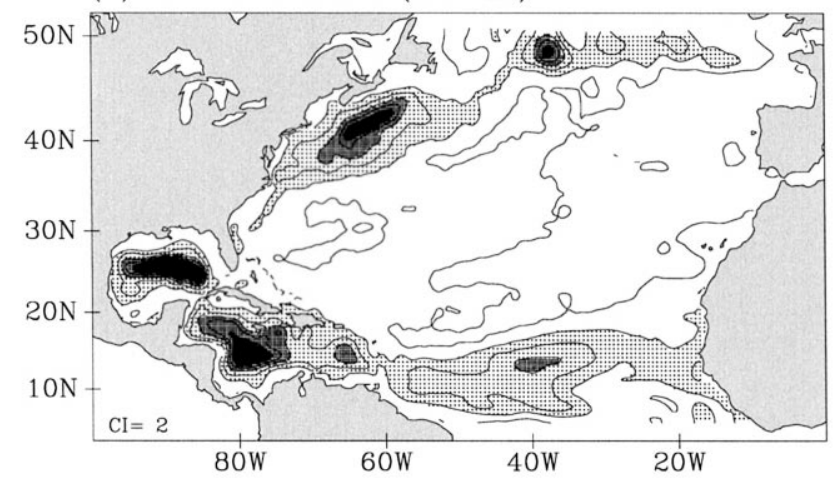

(C) RMS SURF. ELEV. (EXP. L4)

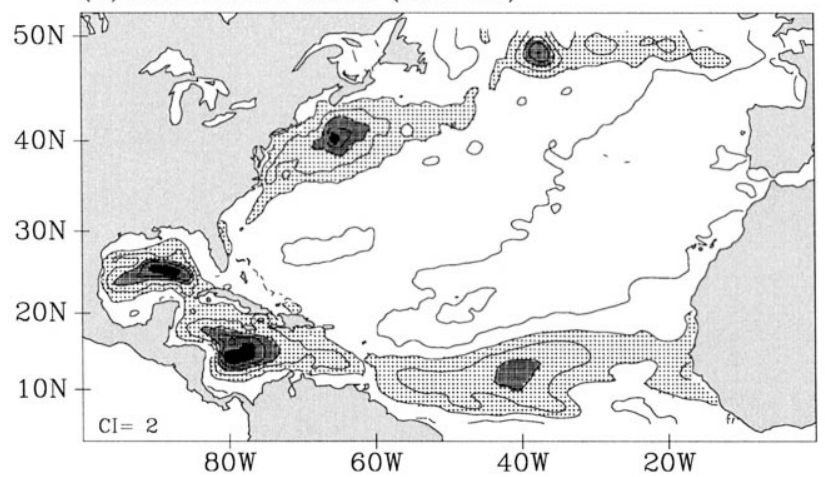

Fig. 12. Rms surface elevation calculated from 3 years (years 4-6) of integration with the low resolution grids of experiments (A) L2, (B) L3 and (C) L4. Contour interval is $2 \mathrm{~cm}$; dotted, dashed and dark shaded regions represent values of $4-8 \mathrm{~cm}, 8-12 \mathrm{~cm}$ and greater than $12 \mathrm{~cm}$, respectively.

separation is somewhat better than the other experiments, possibly due to a smaller climate drift of the density field in this simulation (Fig. 8) which helps to maintain the 
(A) MEAN SURF. ELEV. (EXP. H1)

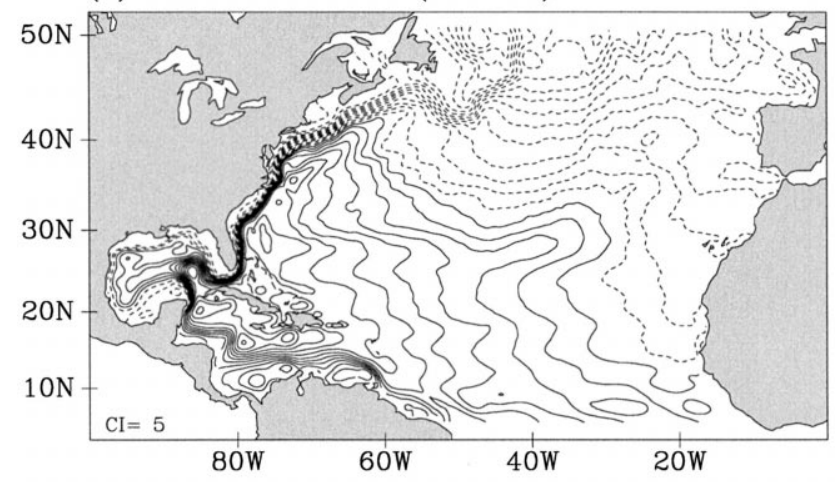

(B) MEAN SURF. ELEV. (EXP. H2)

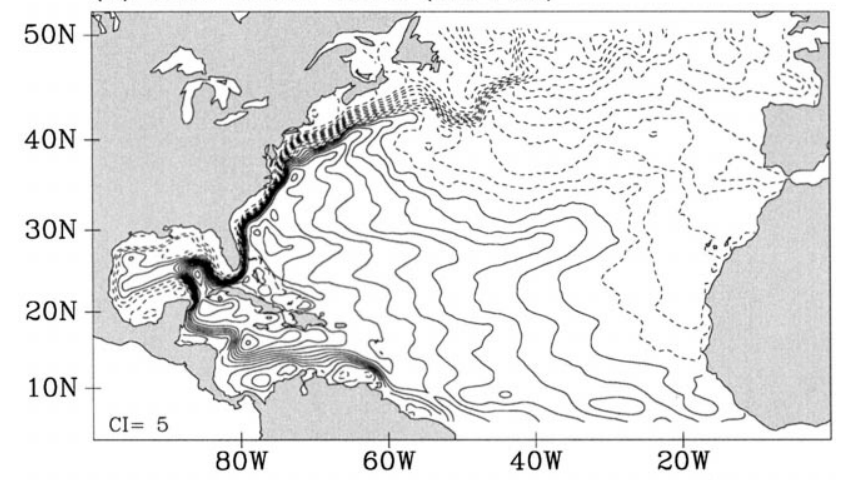

(C) MEAN SURF. ELEV. (EXP. H3)

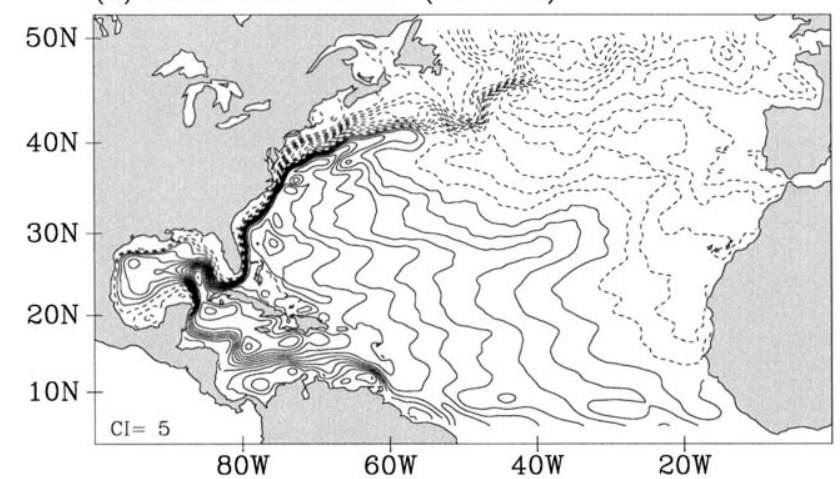

Fig. 13. Same as Fig. 11, but for the high resolution experiments (A) H1, (B) H2 and (C) H3.

baroclinic structure across the Gulf Stream. In contrast with the small effect, the diffusivity has on the mean elevation, the surface elevation variability obtained by the different low resolution calculations differ from each other, and the effect of diffusivity 
(A) RMS SURF. ELEV. (EXP. H1)

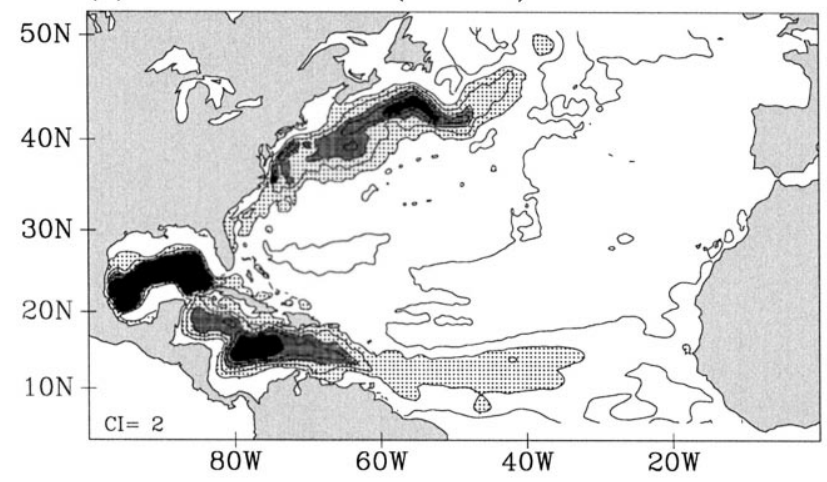

(B) RMS SURF. ELEV. (EXP. H2)

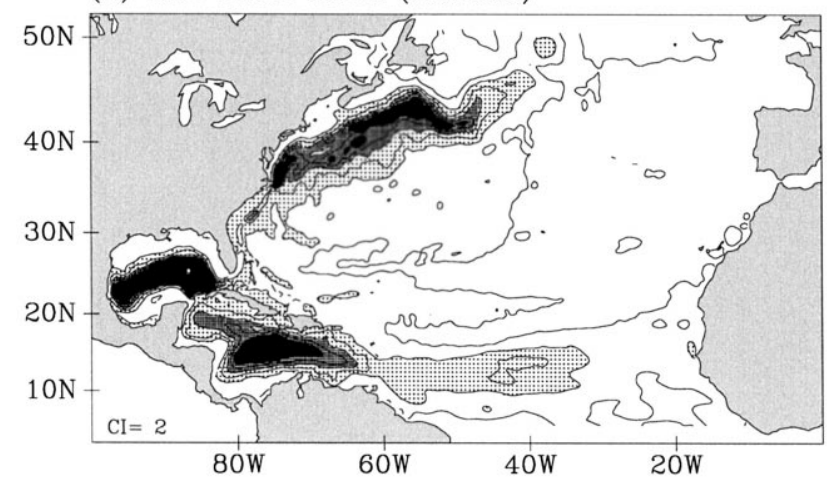

(C) RMS SURF. ELEV. (EXP. H3)

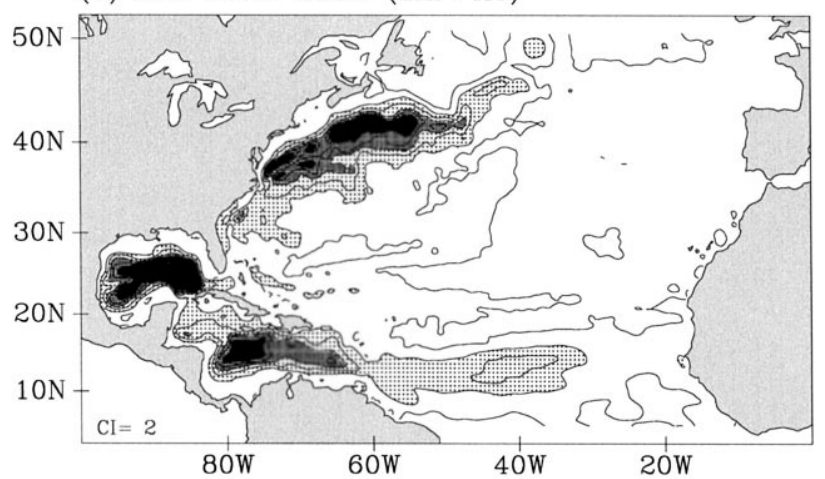

Fig. 14. Same as Fig. 12, but for the high resolution experiments (A) H1, (B) H2 and (C) H3.

changes between one region to another (Fig. 12). For example, experiment L2 with the higher diffusivity (Fig. 12A) has the largest area of high variability in the Gulf Stream 
region, while experiment L3 (Fig. 12B) with the lowest diffusivity has the largest area of high variability in the Gulf of Mexico region where the model is eddy resolving. The relation between the mean location of the Gulf Stream (Fig. 11) and the variability (Fig. 12) suggests that the decrease in Gulf Stream variability in L3 and L4 is related to a more northward and less realistic position of the stream. We note that the high variability along the northern lateral boundary seem to be related to instabilities associated with adjustment of the flow field near the buffer zone.

(a) $70 \mathrm{~W}$

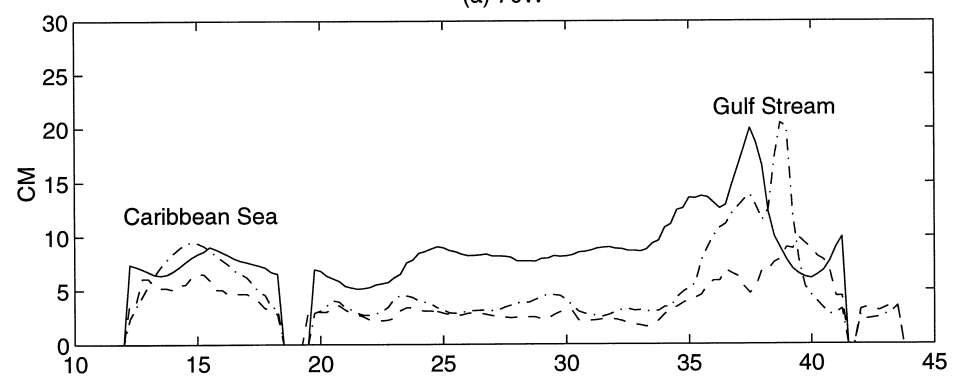

(b) $65 \mathrm{~W}$

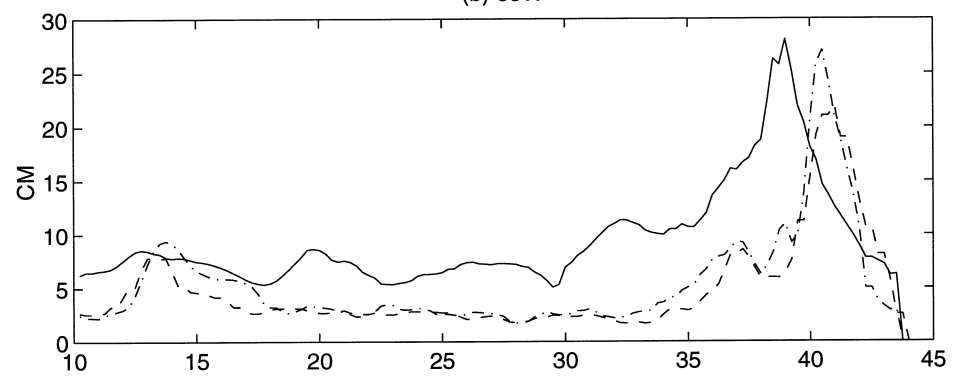

(c) $60 \mathrm{~W}$

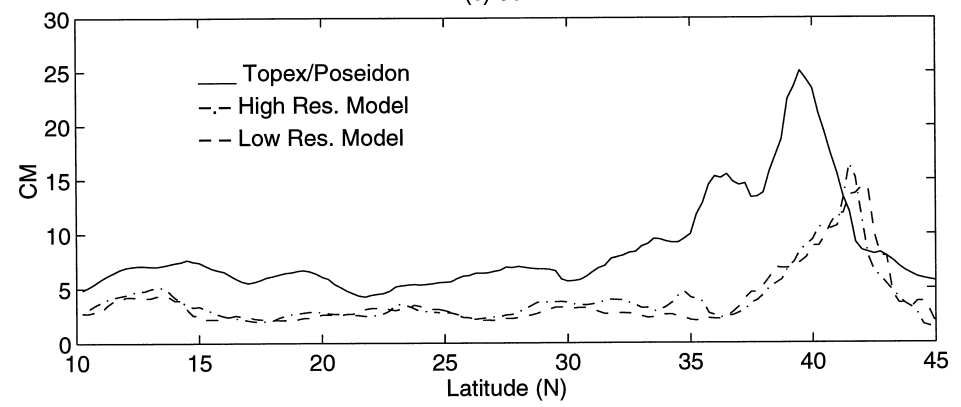

Fig. 15. A comparison between the variability ( $\mathrm{rms}$ surface elevation anomaly) obtained from the Topex/Poseidon altimeter (solid lines) and the variability obtained from the high resolution (H3) (dash-dot lines) and the low resolution (L2) (dashed lines) models along three north-south sections: (a) $70^{\circ} \mathrm{W}$, (b) $65^{\circ} \mathrm{W}$ and (c) $60^{\circ} \mathrm{W}$. Model calculations are from the 3-year simulations shown in Figs. 12a and 14c; altimeter calculations were obtained from data collected during 1993-1995. 
We now turn to the high resolution calculations. While the Gulf stream and the Gulf of Mexico loop current in the high resolution calculations (Fig. 13) are better defined and more intense than those obtained by the lower resolution grid (Fig. 11), discussed above, the Gulf Stream separation is still not satisfactory and an even higher resolution grid is probably needed, as indicated by Hulbert and Hogan (2000, this issue). The mean Gulf Stream position is somewhat more realistic in H3 (Fig. 13C), which has a higher diffusivity than the other high resolution experiments; this is especially evident between $50^{\circ} \mathrm{W}$ and $60^{\circ} \mathrm{W}$. This result is consistent with the low resolution calculations, i.e., experiments $\mathrm{L} 2$ and $\mathrm{H} 3$ with $C_{\mathrm{vis}}=C_{\mathrm{dif}}=0.1$ seem to produce the best results. The spatial distribution of rms elevation in the high resolution calculations (Fig. 14) shows that the area of high variability extends farther downstream along the Gulf Stream path compared with the low resolution calculations (Fig. 12). A significant increase in the area of large variability in the high resolution calculations, compared with the lower resolution calculations, is seen in the Gulf of Mexico, where the eddies shed from the loop current are more intense and maintain their character for longer period of time. As with the low resolution experiments, a Gulf Stream path too close to the continental slope (e.g., as in H1 and H2) seems to relate to a lower Gulf Stream variability.

The surface elevation variability of the low (L2) and high (H3) resolution calculations across the Gulf Stream are now compare with the variability obtained from the Topex/Poseidon altimeter (Fig. 15). Both, the low and the high resolution models underestimate the variability in the open ocean, compared to observations, by about a factor of 2. In the relatively high resolution Caribbean Sea, both models calculate quite realistic variabilities (Fig. 15a). At all three sections, the model Gulf Stream is found north of the observed location, a result of the Gulf Stream separation problem, as discussed before. However, the maximum variability in the high resolution model is comparable to the observed variability at $65^{\circ} \mathrm{N}$ and at $70^{\circ} \mathrm{N}$ (Fig. 15a and b). Further downstream, at $60^{\circ} \mathrm{W}$, the extension of the model Gulf Stream is too weak in both resolutions and the variability is only about half of the observed variability. This comparison, while showing some improvement as model resolution increases, clearly indicate that even higher model resolution is needed.

\section{Discussion and conclusions}

Free surface sigma coordinate ocean models, such as the POM, are now being used for variety of applications, ranging from small-scale process studies and coastal and estuarine modeling and prediction to basin-scale ocean circulation and climate change modeling (see, for example, Ezer, 1996, for a summary of POM applications). Therefore, it is important to systematically evaluate the sensitivity of the model to various parameters, to help users choose the best parameters for their particular application. The model configuration tested here includes the North Atlantic basin from $5^{\circ} \mathrm{N}$ to $50^{\circ} \mathrm{N}$ and uses a curvilinear orthogonal grid with higher resolution in the western North Atlantic and lower resolution in the eastern North Atlantic; this model domain is also covered by other types of models as part of the Data Assimilation and Model Evaluation Experiments in the North Atlantic Basin (DAMEE-NAB). 
The choice of lateral boundary conditions is a major problem in regional ocean models. Two different boundary conditions were tested here, a closed boundary condition with no flow across the solid north and south boundaries, typical of many basin scale models (Beckmann et al. 1994; Chassignet et al. 1996), and an open boundary condition wherein the transport through the boundaries are imposed from a large scale climate model of the entire Atlantic Ocean (Ezer and Mellor, 1997). In both cases, temperature and salinity fields are relaxed towards the monthly climatological fields in buffer zones near the boundaries. The flow field is expected to adjust to the density field within the buffer zones. However, the experiments show that in the case of closed boundaries, the buffer zones are unable to produce enough barotropic western boundary inflow from the north; consequently, the northern recirculation gyre north of the Gulf Stream is too weak and the Gulf Stream separates from the coast farther north, compared with the case with open boundary conditions. A similar result was obtained in the Gulf Stream separation study of Ezer and Mellor (1992), using a smaller domain. In most of the previous regional applications of POM (e.g., Ezer and Mellor, 1992, 1994) buffer zones were not used; instead seasonal temperature and salinity are advected into inflow open boundaries. Even with open boundary conditions, the separation of the Gulf Stream, though improved by intensifying the northern recirculation gyre, is still not satisfactory. The location of the northern boundary at $50^{\circ} \mathrm{N}$ (an imposed requirement in the DAMEE intercomparison study), which is close to the Gulf Stream and in a region of intense exchange of water masses, is probably not the best choice. A model based on POM which extends further north into the Greenland Sea (Ezer and Mellor, 1997; Ezer, 1999) seems to produce a more realistic Gulf Stream separation than the current limited area model. It is also clear that the model resolution here is insufficient and in fact, Hulburt and Hogan (2000, this issue) suggest that a grid resolution, higher than $1 / 16^{\circ}$ may be needed to produce realistic Gulf Stream separation.

An area of some concern in using a bottom following sigma coordinate system is the along-sigma horizontal diffusion formulation (Mellor and Blumberg, 1985). The vertical component of the diffusion term over steep topography may increase diapycnal mixing; a solution of this problem is to subtract climatological fields in the diffusion formulation as shown in Eq. (2). The sensitivity experiments indeed, indicate that using this approach with a moderate value of the diffusion and viscosity coefficients in Eq. (1), say 0.1 as in L2 and H3, gives the best results for this particular application. A choice of zero diffusivity is numerically possible even in low resolution sigma models, but it produces some noise. The relaxation to climatology associated with Eq. (2) helps to reduce the model climate drift. This relaxation is very weak however and thus allows seasonal, mesoscale and interannual variabilities to exist (Ezer and Mellor, 1997). Another possible alternative to reducing the diapycnal mixing is using isopycnally oriented diffusion, as has been done in some applications of SPEM (Barnier et al. 1998).

The Smagorinsky-type formulation of diffusion in Eq. (1) seems to be a good choice in models that use irregular grids, as in our experiments, and implies that diffusion and viscosity are proportional to the square of the grid size. However, the results do not show a simple relation between grid size and variability since the effect of diffusion on different parts of the domain is strongly related to the particular characteristics of the local dynamics. For example, variability in the eastern North Atlantic is not sensitive at 
all to the choice of diffusion and viscosity, but variability in the western North Atlantic is. Decreasing grid size by only $50 \%$ causes Gulf Stream variability to increase by a factor of 2 and, in some places, the maximum model variability is comparable to observations. It is likely that there is a threshold of resolution for each region to accurately produce the observed variability; we have not reached this resolution in most of the present model domain.

\section{Acknowledgements}

Two anonymous reviewers are thanked for their useful comments and suggestions. R. Cheney is thanked for providing us with the altimeter data. The collaboration with the DAMEE-NAB group was very helpful and provided us access to several data sets used in this and other studies. The research was supported by the Office for Naval Research, Ocean Modeling and Prediction Program, grant N00014-93-1-0037. Computational resources were provided by the NOAA's Geophysical Fluid Dynamics Laboratory.

\section{References}

Aikman, F., Mellor, G.L., Ezer, T., Shenin, D., Chen, P., Breaker, L., Bosley, K., Rao, D.B., 1995. Toward an east coast operational nowcast/forecast system. In: Malanotte-Rizzoli, P. (Ed.), Modern Approaches to Data Assimilation in Ocean Modeling vol. 61 Elsevier, Amsterdam, pp. 347-376.

Barnier, B., Marchesiello, P., De Miranda, A.P., Molines, J.-M., Coulibaly, M., 1998. A sigma-coordinate primitive equation model for studying the circulation in the South Atlantic: Part I. Model configuration with error estimates. Deep-Sea Res. 45, 543-572.

Beckmann, A., Boning, C.W., Koberle, C., Willebrand, J., 1994. Effects of increased horizontal resolution in a simulation of the North Atlantic ocean. J. Phys. Oceanogr. 24, 326-344.

Blumberg, A.F., Mellor, G.L., 1987. A description of a three-dimensional coastal ocean circulation model. In: Heaps, N.S. (Ed.), Three-Dimensional Coastal Ocean Models vol. 4 American Geophysical Union, Washington, DC, pp. 1-16.

Chassignet, E.P., Smith, L.T., Bleck, R., Bryan, F.O., 1996. A model comparison: Numerical simulations of the North and Equatorial Atlantic oceanic circulation in depth and isopycnic coordinates. J. Phys. Oceanogr. 26, 1849-1867.

da Silva, A.M., Young, C.C., Levitus, S., 1994. Atlas of surface marine data 1994, Vol. 3, Anomalies of heat and momentum fluxes. NOAA Atlas NESDIS 8, 413 pp., NOAA, Washington, DC.

Dengg, J., Beckmann, A., Gerdes, R., 1996. The Gulf Stream separation problem. In: Krauss, W. (Ed.), The Warmwatersphere of the North Atlantic Ocean. Gebr. Borntraeger Science Publishers, pp. 253-290.

Ezer, T. (Ed.), Proceedings from the Princeton Ocean Model (POM) Users Meeting, Program in Atmospheric and Oceanic Sciences, Princeton University, 56 pp.

Ezer, T., 1999. Decadal variabilities of the upper layers of the subtropical North Atlantic: an ocean model study. J. Phys. Oceanogr. 29, 3111-3124.

Ezer, T., Mellor, G.L., 1992. A numerical study of the variability and the separation of the Gulf Stream induced by surface atmospheric forcing and lateral boundary flows. J. Phys. Oceanogr. 22, 660-682.

Ezer, T., Mellor, G.L., 1994. Diagnostic and prognostic calculations of the North Atlantic circulation and sea level using a sigma coordinate ocean model. J. Geophys. Res. 99, 14159-14171.

Ezer, T., Mellor, G.L., 1997. Simulations of the Atlantic Ocean with a free surface sigma coordinate ocean model. J. Geophys. Res. 102, 15647-15657.

Haney, R., 1971. Surface thermal boundary condition for ocean circulation models. J. Phys. Oceanogr. 1, $241-248$. 
Hogg, N.G., Pickart, R.S., Hendry, R.M., Smethie, W.J., 1986. The northern recirculation gyre of the Gulf Stream. Deep-Sea Res. 33, 1139-1165.

Hulburt, H.E., Hogan, P.J., 2000. Impact of $1 / 8^{\circ}$ to $1 / 64^{\circ}$ resolution on Gulf Stream model-data comparison in basin-scale subtropical Atlantic Ocean models. Dyn. Atmos. Oceans 32, 283-329.

Mellor, G.L., Blumberg, A.F., 1985. Modeling vertical and horizontal diffusivities with the sigma coordinate system. Mon. Weather Rev. 113, 1380-1383.

Mellor, G.L., Yamada, T., 1982. Development of a turbulent closure model for geophysical fluid problems. Rev. Geophys. 20, 851-875.

Mellor, G.L., Ezer, T., Oey, L.-Y., 1994. The pressure gradient conundrum of sigma coordinate ocean models. J. Atmos. Ocean Tech. 11, 1126-1134.

Mellor, G.L., Oey, L.-Y., Ezer, T., 1998. Sigma coordinate pressure gradient errors and the seamount problem. J. Atmos. Ocean Tech. 15, 1122-1131.

Mellor, G.L., Häkkinen, S., Ezer, T., Patchen, R., 2000. A generalization of a sigma coordinate ocean model and an intercomparison of model vertical grids. In: Pinardi, N. (Ed.), Ocean Forecasting: Theory and Practice. Springer-Verlag, in press.

Myers, P.G., Fanning, A.F., Weaver, A.J., 1996. JEBAR, bottom pressure torque and Gulf Stream separation. J. Phys. Oceanogr. 26, 671-683.

Oey, L.-Y., 1996. Simulation of mesoscale variability in the Gulf of Mexico: sensitivity studies, comparison with observations and trapped wave propagation. J. Phys. Oceanogr. 26, 145-175.

Smagorinsky, J., Manabe, S., Holloway, J.L., 1965. Numerical results from a nine-level general circulation model of the atmosphere. Mon. Weather Rev. 93, 727-768.

Teague, W.J., Carron, M.J., Hogan, P.J., 1990. A comparison between the Generalized Digital Environmental Model and Levitus climatologies. J. Geophys. Res. 95, 7167-7183.

Willems, R.C., Glenn, S.M., Crowley, M.F., Malanotte-Rizzoli, P., Young, R.E., Ezer, T., Mellor, G.L., Arango, H.G., Robinson, A.R., Lai, C.-C.A., 1994. Experiment evaluates ocean models and data assimilation in the Gulf Stream. EOS, Trans. Am. Geophys. Union 75, 385-394. 